\title{
Noticias SEDIC
}

\section{Nueva Web de los Labsbibliotecarios}

La Dirección General del Libro y Fomento de la Lectura ha lanzado un proyecto colaborativo con Medialab Prado del Ayuntamiento de Madrid creado en 2017. Su objetivo es reforzar la idea de la biblioteca como un espacio de encuentro de la ciudadanía para el desarrollo de proyectos. En un principio se han incorporado 48 laboratorios ciudadanos a la Web y se espera que su número aumente. El Ministerio de Cultura se une así a los proyectos que se han desarrollado en diferentes ámbitos bibliotecarios mediante una plataforma que les ha sido facilitada.

El Ministerio de Cultura presentó en octubre una nueva página web del proyecto. En el anuncio de la Web por dicho Ministerio se define este espacio: "La web de los LabsBibliotecarios es un espacio que sirve para alojar las acciones realizadas en el marco de este proyecto cooperativo. Se trata de una herramienta que la Subdirección General de Coordinación Bibliotecaria pone a disposición de todos los participantes de esta iniciativa, y que permite documentar y visibilizar todos los laboratorios que se hayan puesto en marcha gracias a ésta". Con respecto al funcionamiento de la Web se señala: "En consonancia con el espíritu de la propuesta, esta es una web en la que cada persona que organiza el laboratorio o que promueve un proyecto tiene un espacio donde documentarlos, dándole así mayor visibilidad. Se puede escoger entre distintos roles: organizador/a de laboratorio, promotor/a de proyecto, colaborador/a. Cada uno de estos roles tiene permisos para realizar distintas acciones dentro de la web, que permite, además, que las personas que forman parte de la comunidad puedan alimentar la pestaña "Actualidad" con noticias relacionadas con el mundo de las bibliotecas o la participación ciudadana. Todo esto se complementa con un foro que, gracias a la tecnología de Sindicación de Contenidos, cuenta con un sistema de notificaciones en tiempo real. Cada contenido de la web genera automáticamente una conversación en el foro, que se refleja tanto en el mismo como en la sección "Comentarios".

\section{El nuevo edificio para el archivo histórico provincial en el hospital de la Concepción de Burgos más cerca de ser una realidad}

Recientemente se ha publicado una noticia positiva para el mundo de los archivos y de la protección del patrimonio documental español. El Ministerio de Cultura continúa apostando por la creación de espacios adecuados para albergar los fondos documentales del patrimonio histórico provincial. Este proyecto es fruto de la colaboración entre el Ministerio de Cultura y Deporte, la Consejería de Cultura y Turismo de la Junta de Castilla y León, el Ayuntamiento de Burgos y la Universidad de Burgos.

La Gerencia de Infraestructuras y Equipamientos de Cultura ha publicado en el BOE (Boletín Oficial del Estado) la licitación de la redacción del proyecto para la rehabilitación del 
Hospital de la Concepción de Burgos como Archivo Histórico Provincial, comprendiendo: Servicio de redacción de proyectos: básico, de ejecución y de actividad, realización de trabajos complementarios, dirección facultativa completa y coordinación de seguridad salud en fase de ejecución de las obras de rehabilitación del antiguo Hospital de la Concepción de Burgos y construcción de un nuevo edificio anejo para su uso como Archivo Histórico Provincial de Burgos y otros usos culturales. El contrato tiene previsto un plazo de ejecución de 46 meses, se pretende realizar entre los años 2023 y 2025. permitirá realizar un uso compartido del Hospital de la Concepción compatibilizando los servicios archivísticos con el uso universitario del inmueble. Realmente el Archivo Histórico Provincial se ubicará en una ampliación con un edificio de nueva planta, es decir, en un edificio anexo.

Según fuentes del Ministerio de Cultura y Deporte, se va a respectar el carácter de BIC del inmueble del Hospital en la rehabilitación y ampliación del nuevo edificio para Archivo. La inversión de la ejecución de las obras de rehabilitación se eleva a 16.638.169 millones de euros (sin IVA). El Archivo Histórico Provincial contará con 3.142 metros cuadrados. La zona del Archivo tendrá aulas, salas de consulta, biblioteca, espacios para los investigadores, zonas de depósito, despachos, talleres de restauración, digitalización y encuadernación.

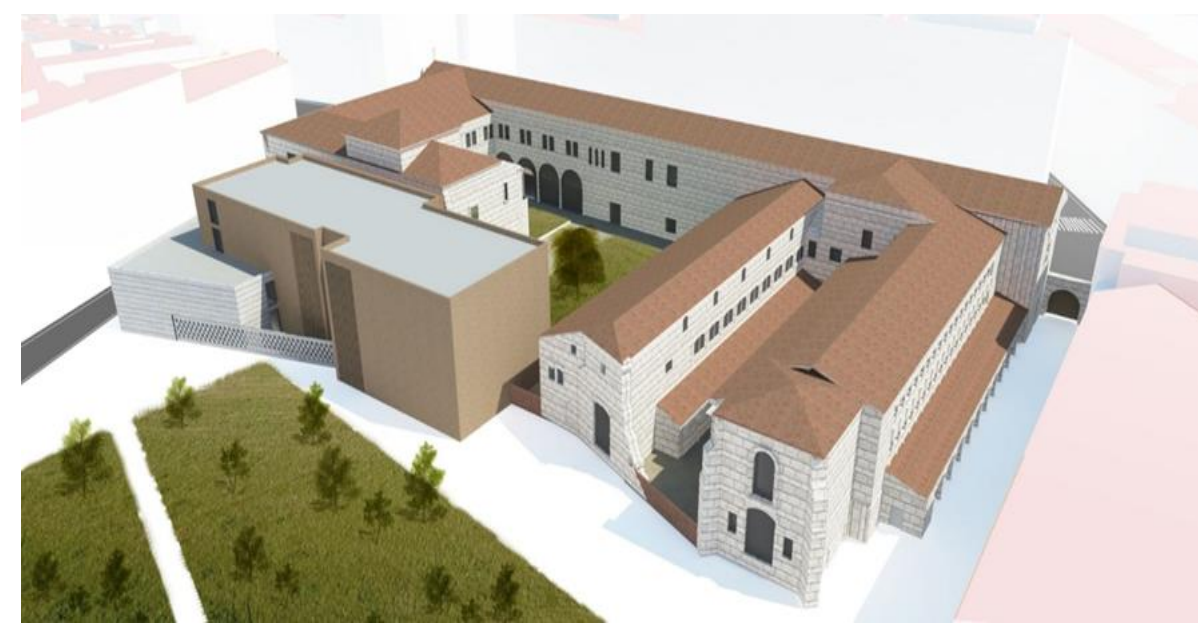

Fuente:

https://www.culturaydeporte.gob.es/giec/ca/obras/proyectos/archivos/burgos.html

Los organismos internacionales como el ICOM, la IFLA o la UNESCO alzan su voz sobre la situación futura del patrimonio cultural de Afganistán

Debido al abandono de los estadounidenses y los aliados de la OTAN de Afganistán después de 20 años de operaciones militares sobre el país, diversos organismos internacionales han realizado declaraciones por el aumento de la preocupación en relación a la conservación futura del patrimonio histórico, artístico y cultural de dicho país, fundamentalmente debido a los trágicos antecedentes de destrucción y de venta indiscriminada de dichos bienes realizados durante la última guerra. Ante todo, los organismos esperan que las autoridades que gobiernan el país, sigan cumpliendo las obligaciones internacionales de protección del patrimonio establecidas en la Convención de La Haya de 1954 para la Protección de los Bienes Culturales y sus protocolos y de la Convención de la UNESCO de 1970 sobre las medidas que deben de adoptarse para 
prohibir e impedir la importación, la exportación y la transferencia de propiedad ilícita de bienes culturales.

Por parte de la IFLA, Christine Mackenzie y Gerald Leitner, Presidenta y Secretario de la organización llamaron la atención de la comunidad internacional a través de una declaración sobre la situación en Afganistán, publicada el 18 de agosto de 2021. En dicha declaración destacan la preocupación por los grupos más vulnerables de la población afgana, concretamente, mujeres y niñas. Haciendo hincapié en los derechos humanos, y en concreto, en el derecho a la educación y el acceso a la información, así como la libertad de opinión y expresión, y los derechos culturales de todos. Para garantizar esos derechos, la declaración indica que es importante el deber de proteger el diverso patrimonio cultural, tanto tangible como intangible. Poniendo énfasis en la necesidad de mitigar las amenazas relacionadas con el tráfico ilícito y el robo de bienes culturales, siendo especialmente vulnerable el patrimonio documental. Dicha protección, señalan en dicha declaración, debe de realizarse sin discriminación por étnica, género, religión u opinión política.

Ver declaración en:

https://www.ifla.org/es/news/declaracion-de-la-ifla-sobre-afganistan/

Por su parte, el ICOM, muestra su preocupación por la población civil que se dedica a proteger el rico y diverso patrimonio cultural del país. $Y$ muestra su esperanza de que las autoridades sigan respetando la integridad de sus museos, colecciones, sitios patrimoniales, así como de los profesionales que se dedican a la conservación y salvaguarda del patrimonio material como inmaterial, sin distinción de étnica, género u opinión política. ICOM destaca además las actividades que realizó en situ para proteger el patrimonio del pueblo de Afganistán de las amenazas organizando talleres, publicando una Lista Roja de Objetos Culturales en Riesgo para Afganistán y luchando contra el tráfico ilícito de bienes culturales.

Ver declaración en:

http://icom.museum/es/news/comunicado-sobre-la-situaci\%C3\%B3n-del-patrimoniocultural-en-afganistan

La UNESCO se ha unido a esta preocupación en una comunicación realizada por Audrey Azoulay, Directora General de la UNESCO, comprometiéndose a seguir de cerca la situación sobre el terreno para hacer todo los posible para salvaguardar el inestimable patrimonio cultural de Afganistán. La UNESCO ya había trabajado sobre el terreno en la Ciudad Vieja de Herat, en sitios Patrimonio Mundial de la UENSCO como el Minarte y vestigios arqueológicos de Jan y el Paisaje cultura y vestigios arqueológicos del Valle de Bamiyán, así como en el Museo Nacional de Kabul.

Ver noticia en:

https://es.unesco.org/news/afganistan-unesco-pide-que-se-proteja-patrimonio-culturalsu-diversidad

\section{Exposición 2328 reales de vellón del Banco de España}

El Banco de España ha inaugurado una magnífica exposición sobre los orígenes de su colección artística vinculada a Goya. La sala de exposiciones se encuentra en el chaflán de su sede de Civiles, en el Paseo del Arte, y reúne un legado artístico y documental histórico único.

La exposición toma por título la cantidad de dinero que se le pagó a Goya por el primer retrato que realizó para el Banco, recogida en un libro de contabilidad de la época que también 
se expone por primera vez. Esta exposición se puede visitar desde el pasado 14 de octubre hasta el 26 de febrero del 2022, reservando las entradas en la página web.

Página Web de la exposición:

https://coleccion.bde.es/wca/es/secciones/exposiciones/2328-reales-de-vellon--.html

\section{"Se crea" no exento de polémica el archivo de los movimientos sociales}

El 12 de octubre del 2021, el Ministerio de Cultura y Deporte ha publicado un Real Decreto 880/2021, de 11 de octubre, por el que se crea el Archivo Histórico de los Movimientos Sociales. Dicho Archivo, no es de creación de nueva planta, pues realmente incorpora al Ministerio de Cultura y Deporte el antiguo Archivo del Movimiento Obrero que alberga los archivos de las Fundaciones Pablo Iglesias, Largo Caballero e Indalecio Prieto y que se ubica en el edificio del antiguo convento de la Trinidad en Alcalá de Henares.

Dicha creación, no nace exenta de polémica, pues varios medios de comunicación y asociaciones profesionales, entre ellas, SEDIC y la AEFP (Asociación de Archiveros de la Función Pública) se han pronunciado sobre cómo se mantendrá dicha institución, pues en el Real Decreto se especifica que la creación no supondrá incremento del gasto público. Por otro lado, también se han pronunciado sobre otras cuestiones como la falta de referencia a los fondos que alberga actualmente el archivo en el Real Decreto, o la situación de su personal, entre otros aspectos. En la noticia del País publicada el 20 de noviembre del 2021, la presidenta de SEDIC, Yolanda de la Iglesia, manifestaba su inquietud sobre dicha creación: "El problema es la falta de dotación económica. Los archivos que ya hay son el hermano pobre de la gestión de la información en la administración pública. Sin dinero es una propuesta que nos crea mucha incertidumbre".

Real Decreto de creación del Archivo:

https://www.boe.es/buscar/act.php?id=BOE-A-2021-16479

Noticia del País: "El Archivo Histórico de los Movimientos Sociales nace sin dinero extra ni personal específico"

https://elpais.com/cultura/2021-11-20/el-archivo-historico-de-los-movimientos-sociales-nacesin-dinero-extra-ni-personal-especifico.html

\section{Celebración en octubre del 2021 del Congreso Internacional Documentos Accesibles: Las Humanidades Digitales en la Sociedad Económica Matritense de Amigos del País de Madrid}

La Asociación Española de Jóvenes Modernistas está impulsando múltiples actividades para el conocimiento e investigación de las fuentes documentales de archivos y bibliotecas, entre las últimas actividades se ha celebrado un Congreso dedicado a las humanidades digitales, haciendo especial hincapié en el acceso digital a las fuentes para el estudio e investigación de la historia desde el ámbito de los archivos y de las bibliotecas, la unión de la necesidad de búsqueda y acceso inmediato a través de las nuevas tecnologías a la documentación y de la creación de servicios más próximos al usuario ha dado lugar a la acuñación hace años de un nuevo concepto: "humanidades digitales", que ha sido la temática en la que se ha centrado dicho evento. El Congreso se realizado bajo la Dirección de Rafael Maldonado de Guevara y Delgado, de la Universidad Rey Juan Carlos y de Ana Naseiro Ramudo, archivera de la OEPM (Oficina Española de Patentes y Marcas) y vocal de SEDIC. Y ha contado con ponentes destacados del ámbito de 
los archivos y de las bibliotecas y personas relacionadas con el gestión de centros de documentación como: José Ramón Cruz Mundet; Elisa Arroyo, Archivera de la Fundación Tatiana Pérez de Gúzman el Bueno; Mercedes Noviembre, Archivera y Bibliotecaria de la Biblioteca Francisco de Zabálburu; Aránzazu Lafuente Urién, Directora del Archivo de la Nobleza de Toledo; Javier Fernández Fernández, Subdirector del Archivo General del Palacio Real; Emiliano Almansa Rodríguez, Presidente de la empresa pública MAYASA; María de los Ángeles Silvestre Madrid del Archivo Histórico de las Minas de Almadén; Enrique Vidal y Joan Andreu Sánchez, fundadores de Transkriptorium; Ana María López Cuadrado, Jefa del Departamento de Coordinación y Normalización del Archivo Histórico Nacional; Laura Carnelos y Georgina Robinson, Bibliotecaria y Archivera, respectivamente, del Eton College del Reino Unido; María José Badenas Población, Archivera del Museo Nacional de Cerámica y Artes Suntuarias "González Martí", y Ainoa Castro, de la Universidad de Salamanca. El Congreso se cerró con la conferencia de Rogelio Blanco Martínez, Exdirector general del Libro, Archivo y Bibliotecas del Ministerio de Cultura.

El Congreso puede visualizarse en: https://www.youtube.com/watch?v=zAzpauVUnQo 